\title{
Design and field test of crosswise belt type whole plastic-film ridging-mulching corn seeder on double ridges
}

\author{
Fei Dai ${ }^{1}$, Wenjuan Guo ${ }^{2}$, Xuefeng Song ${ }^{1}$, Ruijie Shi ${ }^{1}$, Wuyun Zhao ${ }^{1 *}$, Fengwei Zhang ${ }^{1}$ \\ (1. College of Mechanical and Electrical Engineering, Gansu Agricultural University, Lanzhou 730070, China; \\ 2. School of Cyber Security, Gansu University of Political Science and Law, Lanzhou 730070, China)
}

\begin{abstract}
In order to realize seedbed mechanization of whole plastic-film mulching on double ridges and to overcome the difficulty in crosswise belt type soil covering by whole plastic-film, a kind of crosswise belt type whole plastic-film ridging-mulching corn seeder on double ridges was designed in this study. The key components of the sample machine was designed and its working parameters of seedbed soil covering device, crosswise-belt soil covering mechanism and profiling sowing depth adjustment device were determined. After numerical simulation on the film edge and crosswise soil covering by whole plastic-film on double ridges by discrete element method, the velocity and displacement of the oscillating plate, and the variation rule of amount of covered soil with time were explored. Field test results show that, when the advancing velocity of the machine was $0.50 \mathrm{~m} / \mathrm{s}$, the qualified rate of soil width covered on film edge of the seedbed reached $96.1 \%$, qualified rate of crosswise soil belt width was $94.5 \%$, qualified rate of soil thickness on seedbed was $95.3 \%$, qualified rate of sowing depth was $89.3 \%$, qualified rate of spacing between crosswise soil belts reached $93.6 \%$, which all met related standards in China and satisfied design requirements, and could realize seedbed mechanization of whole plastic-film mulching on double ridges. Comparison tests on working performances of practical soil covering show a basic consistence with the seedbed soil covering simulation, and verified the effectiveness of the soil covering model built by using discrete element method.
\end{abstract}

Keywords: whole plastic-film on double ridges, crosswise belt soil covering, combined machine, discrete element, numerical simulation, field test

DOI: $10.25165 /$ j.ijabe. 20191204.4860

Citation: Dai F, Guo W J, Song X F, Shi R J, Zhao W Y, Zhang F W. Design and field test of crosswise belt type whole plastic-film ridging-mulching corn seeder on double ridges. Int J Agric \& Biol Eng, 2019; 12(4): 88-96.

\section{Introduction}

Whole plastic-film sowing technology on double ridges in arid land is a breakthrough and innovation in the arid areas in northwestern China, and initially proposed for corn production. After finishing tillage, film-mulching and soil covering on the big and small ridges and seedbed, the seeder could sow seeds on the film on the ditches of small ridge ${ }^{[1,2]}$. With its significant performance in drought control and production increase, the whole plastic-film sowing technology on double ridges is extensively promoted and applied in the arid areas in northwestern China. Therefore, it is an inevitable trend to realize mechanized ridging, film-mulching, soil covering and soiling ${ }^{[3,4]}$. Meanwhile, film damage, invalid film-mulching and soil covering during the process of mechanized mulching as well as film uncovering by strong

\section{Received date: 2018-12-17 Accepted date: 2019-05-06}

Biographies: Fei Dai, Associate Professor, PhD candidate, research interests: design of agricultural mechanization equipment, Email: daifei@gsau.edu.cn; Wenjuan Guo, Master candidate, research interests: computer simulation, Email: 565105996@qq.com; Xuefeng Song, Master candidate, research interests: agricultural mechanization engineering, Email: 549349477@qq.com; Ruijie Shi, Master candidate, research interests: agricultural mechanization engineering, Email: 1139230110@ qq.com; Fengwei Zhang, PhD, Professor, research interests: agricultural mechanization engineering, Email: zhangfw@gsau.edu.cn. *Corresponding author: Wuyun Zhao, PhD, Professor, research interests: farm machine and mechanical reliability. College of Mechanical and Electrical Engineering, Gansu Agricultural University, Lanzhou 730070, China. Tel: +86-451-7632472, Email: zhaowy@gsau.edu.cn. winds are the key factors that affect the whole plastic-film sowing technology on double ridges ${ }^{[5-8]}$.

Since the whole plastic-film sowing technology on double ridges has been studied and promoted in the arid and semi-arid areas in northwestern China in recent years, there are few references on related farming system and equipment in foreign countries $^{[9,10]}$. With the sustained development of agricultural technology, some researchers in China jointly designed and developed integrative machine for whole plastic-film mulching and soil covering on double ridges with enterprises. However, there are some deficiencies in such machine. It could only realize vertical laying of the soil belts on film, which is not good for positioning and settlement of film, the laying of crosswise soil belts should be finished by human labor and requires high labor intensity $^{[5]}$. Moreover, the soil elevating part of the machine is transmitted by a canvas belt, which may easily cause slippage and wearing during operation ${ }^{[11,12]}$.

To address the problems and further improve the reliability of seedbed mechanization by whole plastic-film mulching on double ridges and enhance wind resistance ability of film, increase the effects of intercepting rainfall runoff of the film-covered seedbed, improve the infiltration ability of ridge and furrow rainwater. Effectively alleviate the plastic film covered farmland holding water decline problem, on the basis of integrating the agronomic requirements of the whole plastic-film sowing technology on double ridges and current studies, a kind of crosswise belt type whole plastic-film ridging-mulching corn seeder on double ridges was designed in this paper, and the key components of the seeder 
were analyzed, with the aim of solving the problems effectively.

\section{Machine structure and working principles}

\subsection{Structure}

As is shown in Figure 1, the crosswise belt type whole plastic-film ridging-mulching corn seeder is mainly composed of a drive shaft, a hanger, a fertilizer spraying system, a rotary blade group, the crosswise belt soil covering device, a soil covering device on film edge, a film-mulching device, hill-drop planter and a sowing depth adjustment device.
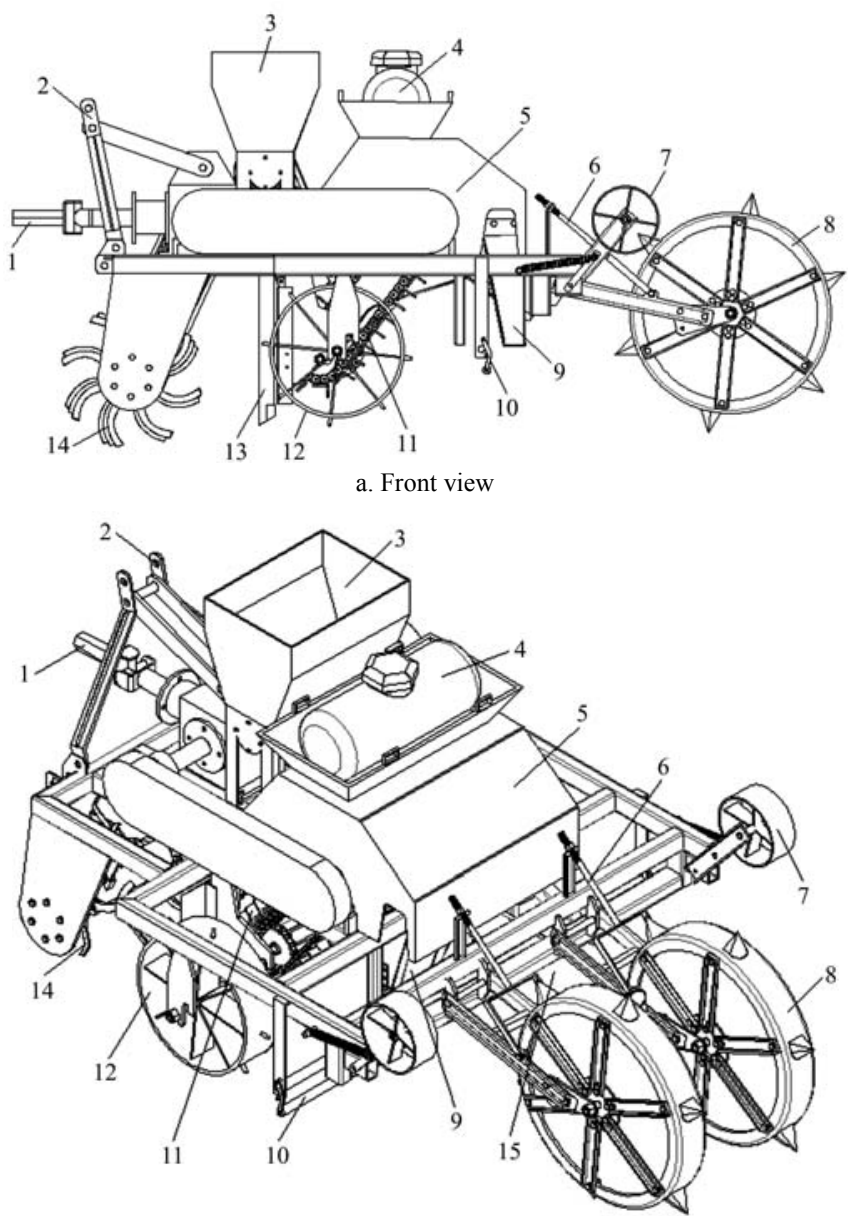

b. Axonometric drawing

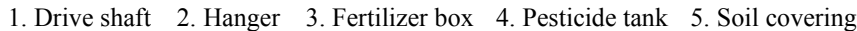
enclosure 6. Sowing depth adjustment device 7. Press wheel 8. Hill-drop planter 9. Side soil groove 10. Film hanger 11. Scraper soil elevator 12. Ground wheel 13. Fertilizer distribution device 14. Rotary blade group 15. Crosswise belt soil covering device

Figure 1 Structure of the crosswise belt type whole plastic-film ridging-mulching corn seeder on double ridges

In working, the seeder covers soil continuously on the film over the big ridges; it covers crosswise soil belts intermittently on the small ridges; and covers soil and sowing seeds continuously in the ditches. The crosswise belt soil covering device is mainly composed of an opening lever, an oscillating plate and reset springs; the sowing adjustment device is mainly composed of positioning screw and four-bar profiling device; film edge soil covering device is mainly made up of scraper type soil elevator and soil covering enclosure; the scraper type soil elevator is mainly made up of elevating belt, soil scraper and the transmission mechanism ${ }^{[13,14]}$.

The structure parameters of crosswise belt type whole plastic-film ridging-mulching corn seeder on double ridges are shown in Table 1.
Table 1 Structural parameters of corn seeder

\begin{tabular}{lcc}
\hline \multicolumn{1}{c}{ Item } & Unit & Parameter \\
\hline Machine size (length $\times$ width $\times$ height) & $\mathrm{m} \times \mathrm{m} \times \mathrm{m}$ & $1.78 \times 1.50 \times 1.05$ \\
Tractor horsepower & $\mathrm{kW}$ & $22.1-29.4$ \\
Linkage & - & three-point suspension \\
Fertilization of rows & - & 2 \\
Operating speed & $\mathrm{km} \cdot \mathrm{h}^{-1}$ & $2.80-3.60$ \\
Productivity & $\mathrm{hm}^{2} \cdot \mathrm{h}^{-1}$ & $0.26-0.40$ \\
Fertilize depth & $\mathrm{mm}$ & $70-90$ \\
Rotary tillage depth & $\mathrm{mm}$ & $100-150$ \\
Ridging height & $\mathrm{mm}$ & $100-150 / 150-200$ \\
Ridging width & $\mathrm{mm}$ & $400 / 700$ \\
Width of crosswise belt soil covering & $\mathrm{mm}$ & $90-110$ \\
Spacing distance of crosswise belt soil covering & $\mathrm{mm}$ & 1500 \\
Thickness of covering soil & $\mathrm{mm}$ & $20-30$ \\
Seedling distance of crop & $\mathrm{mm}$ & $250-350$ (adjustable) \\
Depth of seeding under the film & $\mathrm{mm}$ & $30-50$ (adjustable)
\end{tabular}

\subsection{Analysis of the working process}

As is shown in Figure 2, the seeder is suspended after a four-wheel tractor during field work. The power of the tractor is input into the gearbox and transmitted to rotary tillage blade shaft, which drives the rotary blade group to loosen the soil at the seedbed. There is a fertilizer distribution device under the fertilizer box that fertilizes the ditches on both sides of the small ridge driven by the ground wheel and sprays chemical agents on the big and small ridges; the ground film also rotates synchronously with the rotating mulching device and covers on the soil by the unfolding roller. The seeder delivers soil to the soil covering enclosure through the soil elevator. The soil covering enclosure can divide the soil into four ways, in which the covering soil at both sides of film is delivered by the side soil bin, and other soil drops to the crosswise belt soil covering device under the influence of gravity and discharged to finish soil covering on the ditches. In the meantime, sowing is finished with the help of hill-drop wheels. In addition, with the advancing of the machine, some soil on the crosswise belt soil covering device is discharged through the soil outlet, other soil piles up constantly, and the contact between the opening lever and ground wheel tooth caused intermittent vibration of the oscillating plate, which shakes off the soil on it and finishes crosswise soil belt covering on seedbed with constant spacing of whole plastic-film mulching on double ridges.

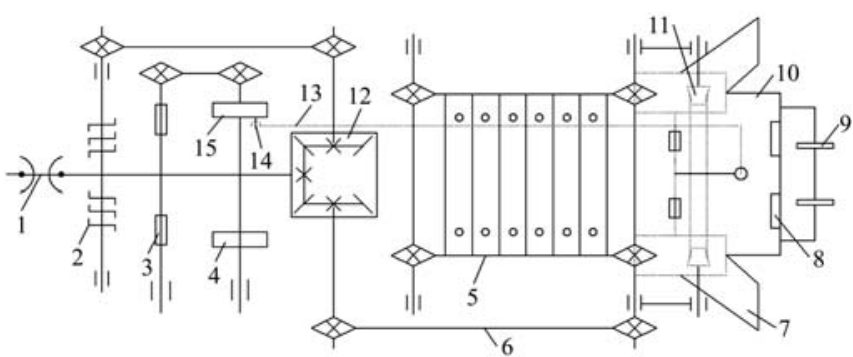

1. Cardan joint 2. Rotary blade group 3. Fertilizer distribution device 4. Ground wheel 5. Scraper type soil elevator 6. Chain drive 7. Side soil groove 8 . Soil outlet 9 . Hill-drop planter 10 . Oscillating plate for crosswise belt soil covering 11. Film hanger 12. Gearbox 13. Opening lever 14. Ground wheel tooth 15 . Ground wheel

Figure 2 Transmission path

\subsection{Agronomic requirements in soil covering}

The corresponding agronomic planting model of the crosswise-belt type whole plastic-film ridging-mulching corn seeder on double ridges is shown in Figure 3. The seedbed of whole plastic-film mulching on double ridges has two big ridges 
and a small ridge, covering a total width of $1100 \mathrm{~mm}$. A big ridge is 700 in width and $100-150 \mathrm{~mm}$ in height; the small ridge is $400 \mathrm{~mm}$ in width and $150-200 \mathrm{~mm}$ in height. The ridges are all covered by film and seeds are sown in the ditches. During mechanized film-mulching and soil covering, white mulching film with width of $1200 \mathrm{~mm}$ (thickness of $0.01 \mathrm{~mm}$ ) was laid by taking the small ridge as the central datum, namely, a whole piece of mulching film is covered on the small ridge and the ditches on both sides. Then, the mulching film is stretched sideways to $1 / 2$ of the big ridges on both sides, and finish soil covering and pressing on film edges and ditches simultaneously. Meanwhile, during the film covering of current small ridge, its left side of the film on the left of $1 / 2$ big ridge is just docked with the film of last set of the right of big ridge, and realizes full-film coverage on big ridge with the connection of central soil belts, and the overall width of the bottom of the double ridge covered by the whole mulch is about $1100 \mathrm{~mm}^{[15,16]}$.

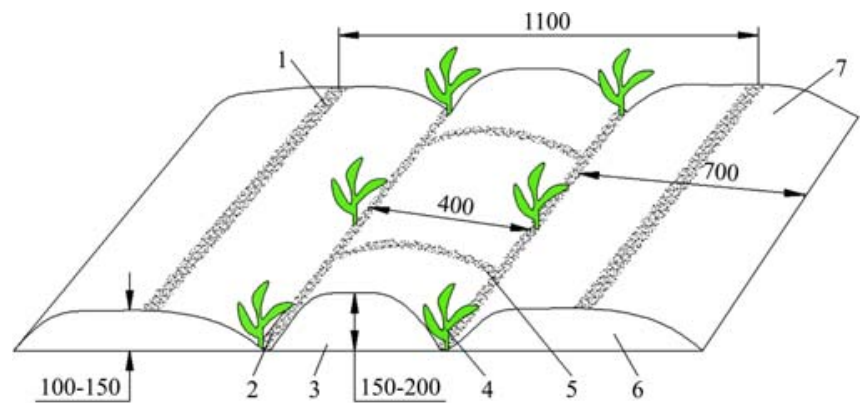

1. Central soil belt on film 2. Soil belt on ridge 3. Small ridge 4. Crops planted in the ditch 5 . Crosswise soil belt 6 . Big ridge 7 . Mulching film

Figure 3 Agronomic cultivation mode for whole plastic-film seeding on double ridges

Meanwhile, in order to further improve the ability of resisting film uncovering by wind of the seedbed and enhance its effect in intercepting rainfall runoff, there should be crosswise soil belt covered with a spacing on the surface of the small ridge. According to the specific requirements on soil covering, the width of the crosswise soil belt is $100 \mathrm{~mm}$, width of soil covered on ditches is $40 \mathrm{~mm}$, the covered soil thickness on each part is $25 \mathrm{~mm}$, and the spacing between crosswise soil belts is $1500 \mathrm{~mm}$.

\section{Simulation and design of key components}

\subsection{Seedbed soil covering device}

As is shown in Figure 4, the seedbed soil covering device is mainly composed of a body frame, a scraper type soil elevator, a crosswise belt soil covering device and a side soil groove. When the seedbed soil covering device is working, the rotary blade group cuts soil at a high speed and throws the soil to the soil elevator, on which the scraper rotates clockwise at a uniform speed and elevates the soil. When the soil is overturned by the soil elevator immediately, the soil drops down under gravity and divides to the soil grooves on both side and the oscillating plate. Since the tilted oscillating plate can shake off soil through intermittent vibration, some soil on the oscillating plate would slide to the ditch of the small ridge through the symmetrical soil outlets, while the remaining soil would drop down with the vibration of the oscillating plate and form the crosswise soil belt.

The soil covering for each part on the whole plastic-film seedbed on double ridges is shown in Figure 5. The width of the scraper type soil elevator $B_{1}=800 \mathrm{~mm}$. Then calculate the overall amount of soil elevated by rotary tillage and soil amount delivered by each component within the working range of the spacing between crosswise soil belts $(1500 \mathrm{~mm})$, in order to further determine the central distance $B_{2}$ between the two soil grooves on both sides.
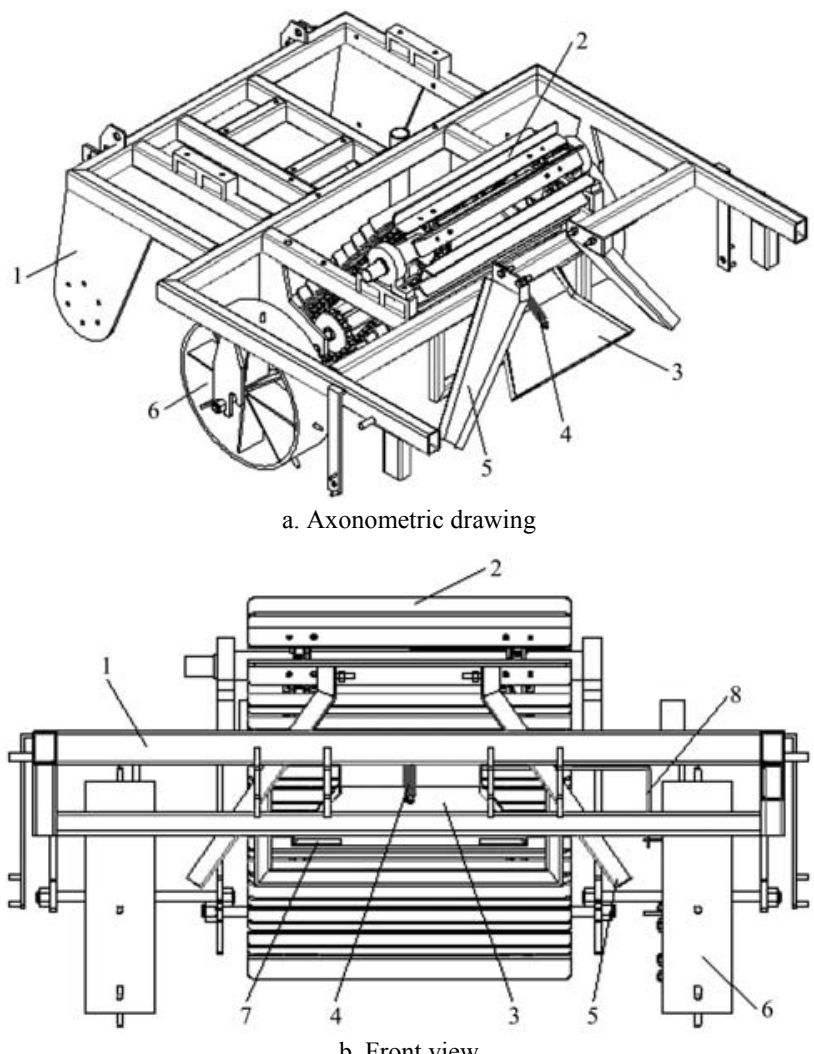

1. Body frame 2. Scraper type soil elevator 3. Oscillating plate 4. Rese spring 5. Side soil groove 6 . Ground wheel 7. Soil outlet 8 . Opening lever

Figure 4 Structure of the soil covering device

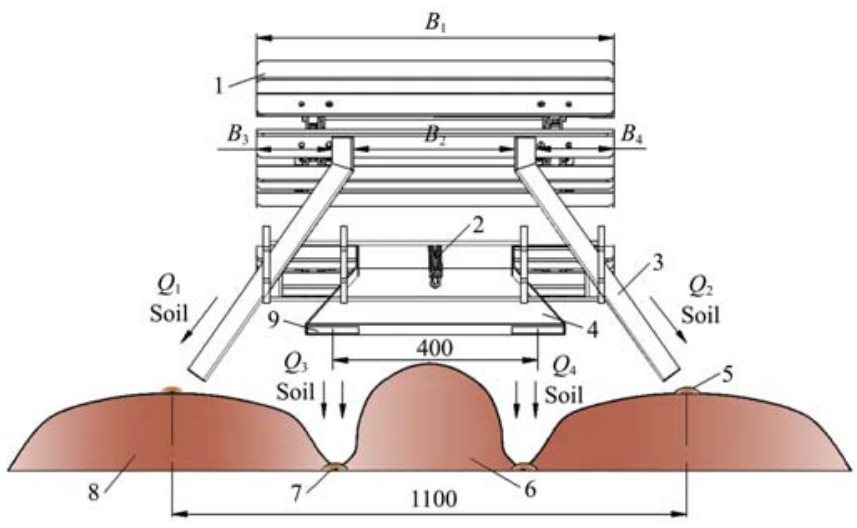

1. Scraper type soil elevator 2 . Reset spring 3 . Side soil groove 4. Oscillating plate 5. Central soil covering belt 6 . Small ridge 7. Soil covering belt on ditch 8. Big ridge 9. Soil outlet

Figure 5 The role of each part of the seedbed in soil covering

Based on the agronomic requirement in soil covering of the seedbed of whole plastic-film mulching on double ridges, then:

$$
\left\{\begin{array}{l}
Q_{Z}=Q_{1}+Q_{2}+Q_{3}+Q_{4}+Q_{5} \\
Q_{1}=Q_{2}=\gamma b_{1} l_{1} h \\
Q_{3}=Q_{4}=\gamma b_{2} l_{1} h \\
Q_{5}=\gamma b_{3} l_{2} h
\end{array}\right.
$$

where, $Q_{Z}$ is the total soil amount covered on the seedbed, kg; $Q_{1}$ is the soil amount covered on the left center of the seedbed, $\mathrm{kg} ; Q_{2}$ is the soil amount covered on the right center of the seedbed, $\mathrm{kg} ; Q_{3}$ is the soil amount on the ditch left of the seedbed, $\mathrm{kg} ; Q_{4}$ is the soil amount covered on the ditch right of the seedbed, kg; $Q_{5}$ is the soil amount at crosswise belt of the seedbed, $\mathrm{kg} ; \gamma$ is the volume weight 
of covered soil (loessal soil), $\mathrm{kg} / \mathrm{m}^{3}$, which is $1300 \mathrm{~kg} / \mathrm{m}^{3} ; b_{1}$ is the width of the central soil belt, mm, which is $100 \mathrm{~mm} ; b_{2}$ is the width of covered soil on ditch, mm, which is $40 \mathrm{~mm} ; b_{3}$ is the width of the crosswise soil belt, mm, which is $100 \mathrm{~mm}$; $h$ is the thickness of soil covered on the seedbed, mm, which $25 \mathrm{~mm} ; l_{1}$ is the spacing distance between crosswise soil belts, $\mathrm{mm}$, which is $1500 \mathrm{~mm}$; $l_{2}$ is the length of crosswise soil belt, $\mathrm{mm}$, which is $410 \mathrm{~mm}$.

Based on Equation (1), it can be obtained that $Q_{1}=Q_{2}=$ $4.875 \mathrm{~kg} ; Q_{3}=Q_{4}=1.95 \mathrm{~kg} ; Q_{5}=1.33 \mathrm{~kg} ; Q_{Z}=14.98 \mathrm{~kg}$. Therefore, by referring to the role of each part of the seedbed in soil covering, it can be concluded that when the machine advances for $1500 \mathrm{~mm}$ in the field, the scraper type soil elevator with a width of $800 \mathrm{~mm}$ can elevate $14.98 \mathrm{~kg}$ soil by rotary tillage, and the soil outlets on both sides could deliver $4.875 \mathrm{~kg}$ respectively, oscillating plate could deliver a total of $5.23 \mathrm{~kg}$ soil.

Compared with the position of scraper type soil elevator on the seedbed soil covering device, the center distance between the soil outlets on both sides $B_{2}$ is the key parameter that influences the working performance in film-mulching and soil covering. When $B_{2}$ is too large, the soil amount in the oscillating plate is too great and may result in wider crosswise soil belt, the constant discharged soil from the oscillating plate may even cover the whole plastic-film; when $B_{2}$ is too small, there would be too much soil going into the soil outlets and result in excessive soil amount in the central soil belt on mulching film and less effective daylighting area for the film on the big ridge, indicating a failure of crosswise soil belt laying. Suppose that the soil is filled uniformly during the work of the scraper type soil elevator, then the valid working length is directly proportional to delivered soil amount, and:

$$
\begin{gathered}
\frac{B_{2}}{B_{3}+B_{4}}=\frac{Q_{3}+Q_{4}+Q_{5}}{Q_{1}+Q_{2}} \\
\left\{\begin{array}{l}
B_{1}=B_{2}+B_{3}+B_{4} \\
B_{3}=B_{4}
\end{array}\right.
\end{gathered}
$$

Based on Equation (2), it can be obtained that the distance between centers of the soil outlets on both sides $B_{2}=0.28 \mathrm{~mm}$; the valid working length between soil outlets and the scraper type soil elevator $B_{3}=B_{4}=0.26 \mathrm{~mm}$.

\subsection{The crosswise belt soil covering mechanism}

The structure of the crosswise belt soil covering mechanism is shown in Figure 6. In working, when the ground wheel makes a round, the tooth on the ground wheel touch the opening lever on the oscillating plate once, then the opening lever drives open the oscillating plate, soil falls down and presses on the film. Finally the crosswise belt soil covering and film pressing is finished and the oscillating plate returns to its original position under the action of the reset spring.

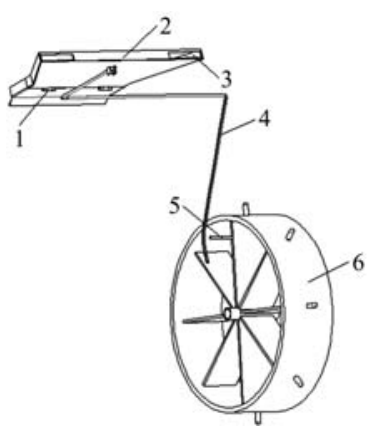

a. Axonometric drawing

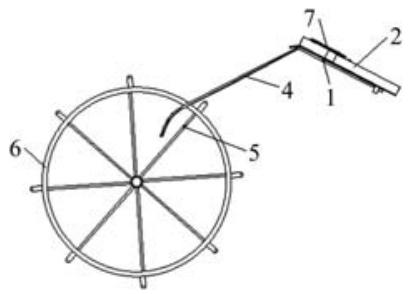

b. Front view
1. Hinge 2. Oscillating plate 3. Soil outlet 4. Opening lever 5. Ground wheel tooth 6. Ground wheel 7. Reset spring

Figure 6 Structure of the crosswise belt soil covering mechanism
In working, when the ground wheel makes a round, the crosswise belt soil covering mechanism opens for one time, and lays soil belt on the seedbed of whole plastic-film mulching on double ridges. The spacing distance between crosswise soil belts $l_{1}$ is $1500 \mathrm{~mm}$, then the diameter of the ground wheel is:

$$
r=\frac{l_{1}}{2 \pi}
$$

where, $l_{1}$ is the spacing distance between crosswise soil belts, $\mathrm{mm}$, which is $1500 \mathrm{~mm}$; $r$ is ground wheel diameter, $\mathrm{mm}$.

It can be obtained from Equation (4) that ground wheel diameter $r=238.8 \mathrm{~mm}$.

According to the advancing velocity of the machine, the vibration frequency of the crosswise belt soil covering device is:

$$
f=\frac{1}{T}=\frac{v_{1}}{l_{1}}
$$

where, $f$ is the vibration frequency of the crosswise belt soil covering device, $\mathrm{Hz} ; T$ is the vibration period of the device, $\mathrm{s} ; v_{1}$ is the advancing velocity of the device, $\mathrm{m} / \mathrm{s}$, which is $0.50 \mathrm{~m} / \mathrm{s}$.

It can be obtained by Equation (5) that, the vibration frequency of the crosswise belt soil covering device $f=0.33 \mathrm{~Hz}$, its vibration period $T=3.03 \mathrm{~s}$, namely, under the linkage of the opening lever and the reset spring, the crosswise belt soil covering mechanism can complete periodic open and close of the oscillating plate within $3.03 \mathrm{~s}$. In the process of operation, the crosswise belt soil covering mechanism could be opened and closed in an orderly way by vibration, and under the action of the opening lever on the oscillating plate, uniform laying of each soil covering belt can be realized, with appropriate soil covering amount and interval is constant to ensure the quality of soil covering of crosswise belt of seed bed.

\subsection{Simulated sowing depth adjustment device}

Since most of the cultivated land in the arid area of northwestern China is hilly land, for convenience of simulation and adjustment of sowing depth, a simulated sowing depth adjustment device was designed. The device is mainly composed of a body frame, a sowing depth adjustment rod, a wheel type hill-drop planter and a profiling mechanism, as is shown in Figure 3. Considering the landform of the film-mulched seedbed, the sowing depth adjustment rod can rotate to adjust sowing depth $(30-50 \mathrm{~mm})$. When the sowing depth adjustment rod extends by rotating counterclockwise, the soil opener moves downward and the sowing depth increases; when the sowing depth adjustment rod turns back, the hill-drop wheel is elevated and the sowing depth reduces ${ }^{[17]}$.

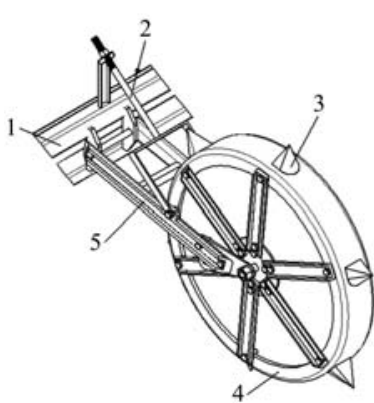

a. Axonometric drawing

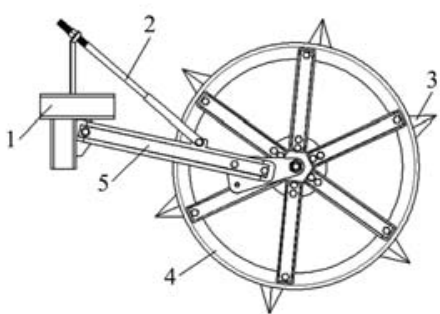

b. Front view
1. Body frame 2. Sowing depth adjustment rod 3. Soil opener 4. Hill-drop wheel 5. Profiling mechanism

Figure 7 Simulated sowing depth adjustment device

The hill-drop wheel mainly sows seeds on the soil-covered belts in the ditches, and the number of soil openers into the soil is jointly determined by wheel radius, hill spacing in sowing and 
sowing depth. Suppose the real rolling radius of the hill-drop wheel is $R s$, then the number of soil openers is:

$$
z=\frac{2 \pi R_{s}}{L}=\frac{2 \pi R+\pi\left(h_{1}+40\right)}{L}
$$

where, $z$ is number of soil openers; $R$ is the radius of the hill-drop wheel, $\mathrm{mm}$, which is $400 \mathrm{~mm}$; $L$ is the seedling distance of crop, which is $300 \mathrm{~mm} ; h_{1}$ is sowing depth, $\mathrm{mm}$, which is $30-50 \mathrm{~mm}$.

Then calculate Equation (6) and round off the result, and the number of soil openers of hill-drop wheel $z=9$.

\section{Simulation and result analysis of the soil covering process}

\subsection{Parameter setting}

In order to further analyze the characteristics of soil elevating, soil delivering, crosswise soil covering and soil covering on film edges during working of the crosswise-belt type whole plastic-film ridging-mulching corn seeder on double ridges, Discrete Element Method (EDEM) was adopted for numerical simulation of the working process of the seedbed soil covering device. For convenience in calculation and analysis on the model, spherical particles with diameter of $3 \mathrm{~mm}$ were adopted as soil particles in the modeling, Hertz-Mindlin (no-slip) was adopted for soil particle-soil particle, soil-particle-scraper type soil elevator, and enclosure wall contact model. The parameters in the simulation test are shown in Table $2^{[18-20]}$.

Table 2 Parameters of materials and contact

\begin{tabular}{clc}
\hline \multicolumn{1}{c}{ Item } & \multicolumn{1}{c}{ Parameter } & Value \\
\hline \multirow{2}{*}{ Soil particles } & Poisson's ratio & 0.4 \\
& Shear modulus/MPa & $1.0 \times 10^{6}$ \\
& Density $/ \mathrm{kg} \cdot \mathrm{m}^{-3}$ & 1364 \\
\hline \multirow{2}{*}{ Scraper and } & Poisson's ratio & 0.28 \\
enclosure wall & Shear modulus/MPa & $3.5 \times 10^{10}$ \\
& Density $/ \mathrm{kg} \cdot \mathrm{m}^{-3}$ & 7850 \\
\hline \multirow{2}{*}{ Particle-particle } & Recovery coefficient & 0.2 \\
& Static friction coefficient & 0.4 \\
& Dynamic friction coefficient & 0.3 \\
\hline Particle-scraper, & Recovery coefficient & 0.3 \\
Enclosure wall & Static friction coefficient & 0.4 \\
& Dynamic friction coefficient & 0.1 \\
\hline
\end{tabular}

Simulation time step is $1.23 \times 10^{-5} \mathrm{~s}$, which is $40 \%$ of Rayleigh time step, and the simulation lasted for $6.50 \mathrm{~s}$. According to the structural design of the seedbed soil covering device, there were 12 scrapers on the scraper type soil elevator, and the distance between every two scrapers was set to $130 \mathrm{~mm}$, and the width was $800 \mathrm{~mm}$. In addition, a complete circle of each scraper includes linear motion and rotary motion, and the velocity of linear soil delivering was $0.50 \mathrm{~m} / \mathrm{s}$; the shaking soil plate is trapezoid-shaped, with the upper top width of $280 \mathrm{~mm}$, and the lower bottom width of $520 \mathrm{~mm}$. It made reciprocating rotation around a fixed axis. The motion of the two components was controlled by dynamic coupling through the coupling server panel in the EDEM. The particle factory was a rectangular plane of $555 \mathrm{~mm} \times 250 \mathrm{~mm}$. The number of soil particles generated per second by the unilateral particle factory is $9.50 \times 10^{4[21,22]}$.

\subsection{Simulation of the seedbed soil covering process}

The software EDEM was applied to simulate the crosswise soil covering and soil covering on film edges by the crosswise-belt type whole plastic-film ridging-mulching corn seeder. Figure $8(\mathrm{a}-\mathrm{i})$ shows the soil elevating and delivering process and the soil covering form of the soil covering device at advancing velocity of $0.50 \mathrm{~m} / \mathrm{s}$ and during period of $t=0.65-6.0 \mathrm{~s}$. Since the soil delivering situation in both soil outlets and the oscillating plate should be observed, the simulation should start after stable elevation of soil by the scraper type soil elevator, therefore, from $t=0.65 \mathrm{~s}$, the EDEM numerical simulation may approximate the working status of the seedbed soil covering, as is shown in Figure 8(a). When $t=1.26 \mathrm{~s}$, there were 3 paths of soil delivery by the soil elevator into the soil outlets and oscillating plate; when $t=$ $1.83 \mathrm{~s}$, the soil on the top of big ridge, ditches of the small ridge and the crosswise soil belts took shape, and the flow velocity of the soil particles at the end of the soil groove was slightly higher than that at the soil outlets (Figure 8c); during $t=2.56-4.66 \mathrm{~s}$ (Figure $8 \mathrm{~d}$, $\mathrm{e}, \mathrm{f}, \mathrm{g})$, the soil particles were relatively full in the oscillating plate and in a relatively static status, in order to generate continuous soil particle flow at the soil outlets and satisfy the agronomic requirements in soil covering of the seedbed of whole plastic-film mulching on double ridges. From $t=5.23 \mathrm{~s}$, there was an accumulated amount of soil on the oscillating plate, and there was some sliding surface soil on the tilted and vibrating plate (with sliding velocity of about $0.2-0.4 \mathrm{~m} / \mathrm{s}$ ), which widened the crosswise soil belt in an unclear shape (Figure 8i), which may easily result in invalid daylighting area on the film-mulched seedbed. Therefore, the working velocity of the oscillating plate, displacement and amount of vibrated soil amount are the key factors that affect the soil belt laying performance.

\subsection{Velocity of the soil covering oscillating plate}

Figure 8 shows that, as long as the scraper-type soil elevator can deliver an appropriate amount of soil, the soil covering operation on the top of the big ridge and in the ditches the small ridges may keep stable; and the laying quality of the crosswise soil belts between the ditches is associated with the velocity and direction of the oscillating plate. For this reason, the variation law of the velocity of the oscillating plate during the whole operation process was measured. Since the oscillating plate is repeatedly opened and closed in the vertical direction, its working variation status during 0-2.5 s was analyzed.

As is shown in Figure 9, the oscillating plate presented maximum velocities in opening at $0.26 \mathrm{~s}$ and $2.09 \mathrm{~s}$, which were $11.6 \mathrm{~mm} / \mathrm{s}$ and $12.71 \mathrm{~mm} / \mathrm{s}$, and at $0.32 \mathrm{~s}$ and $2.15 \mathrm{~s}$, respectively. The maximum velocities in closing were $-145.07 \mathrm{~mm} / \mathrm{s}$ and $-137.58 \mathrm{~mm} / \mathrm{s}$, respectively. It can be concluded that the opening velocity of the oscillating plate is significantly lower than the closing velocity. It can be seen from the curve in Figure 9 that, in order to ensure uniform crosswise soil belts during the opening process of the oscillating plate, its velocity was basically constant; and in order to avoid falling of soil on film on the small ridge after the crosswise soil belts were laid, there was quick-return motion of the oscillating plate during the closing process. The entire opening and closing process of the oscillating plate in laying crosswise soil belts required only $0.06 \mathrm{~s}$, to ensure the accumulation of the soil in the oscillating plate again for subsequent laying of crosswise soil belts.

It can be concluded from the velocity and time variation curve of the oscillating plate that, the velocities of repeated opening and closing of the oscillating plate had some differences in different cycles, but the overall variation trend was basically the same. It is associated with the soil weight and the different terrains of seedbed. 


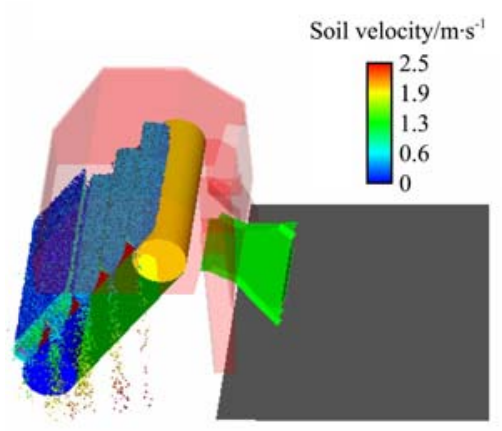

a. $0.65 \mathrm{~s}$

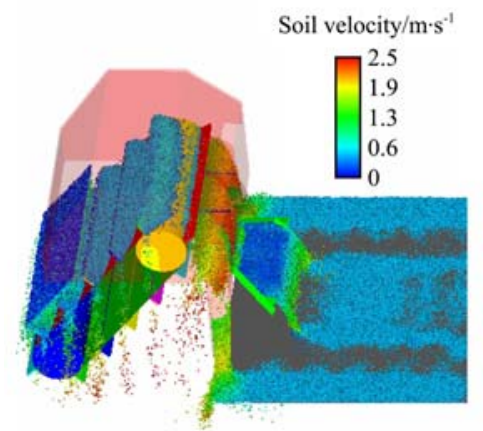

d. $2.56 \mathrm{~s}$

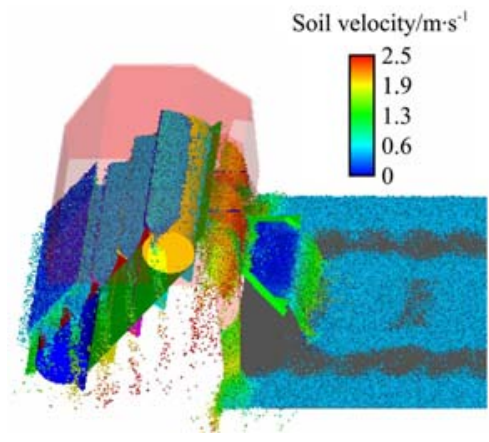

g. $4.66 \mathrm{~s}$

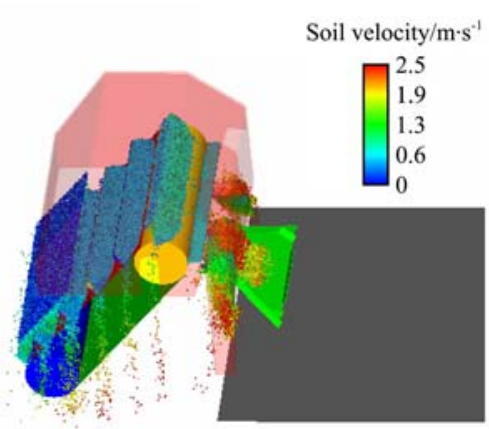

b. $1.26 \mathrm{~s}$

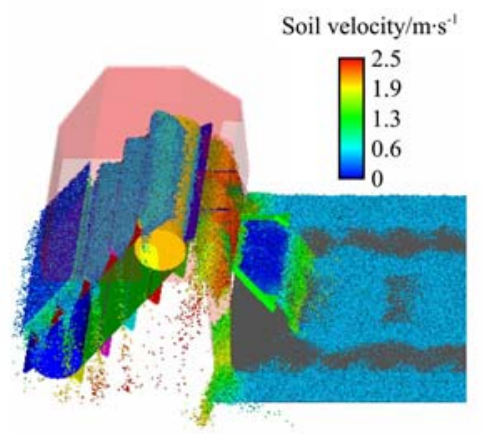

e. $3.12 \mathrm{~s}$

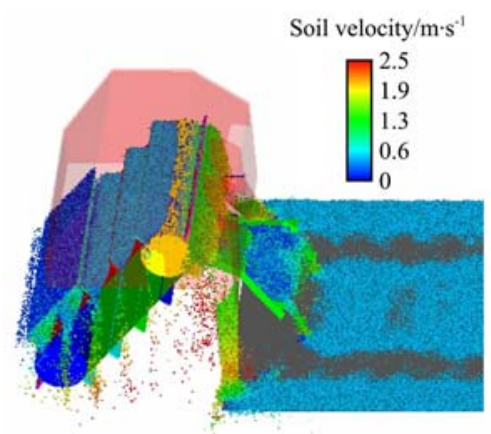

h. $5.23 \mathrm{~s}$

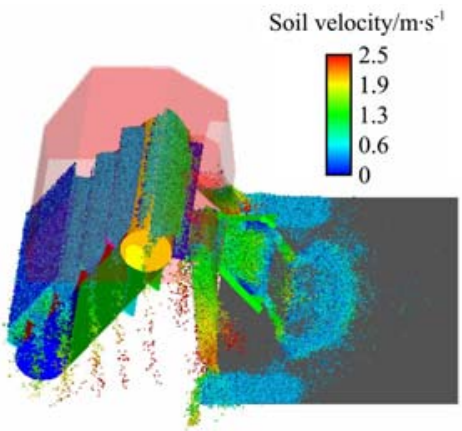

c. $1.83 \mathrm{~s}$

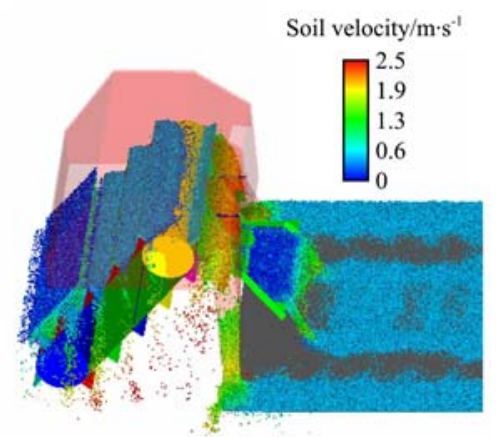

f. $3.96 \mathrm{~s}$

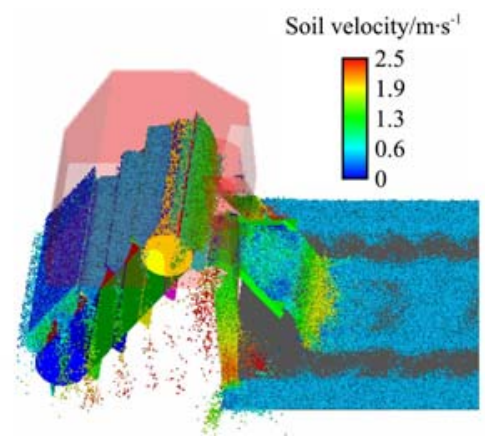

i. $6.00 \mathrm{~s}$

Figure 8 Process and rules for crosswise belt and film edge soil covering

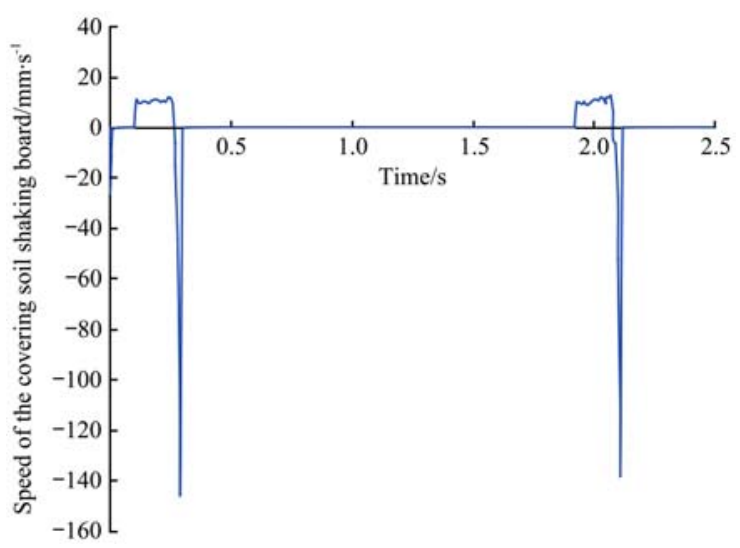

Figure 9 Velocity of the soil covering oscillating plate

\subsection{Displacement of the oscillating plate}

The displacement of the oscillating plate in opening process is the key factor that affects the soil amount of crosswise soil belts and their thickness. If the displacement in opening process is too small, the soil amount shaken off by the oscillating plate is small, and thus cannot meet the requirements of the crosswise soil covering operation on seedbed of whole plastic-film mulching on double ridges, and the crosswise soil covering comes to a failure. When the displacement in opening process is too large, the closing time of the oscillating plate is relatively increased, and may result in insignificant effect of soil covering on the big ridge and reduce effective daylighting area on the film-mulched seedbed and the improving temperature effect of the seedbed of whole plastic-film mulching on double ridges.

As is shown in the curve in Figure 10, during operation of the oscillating plate, the maximum value of displacement in opening process of the oscillating plate at $0.26 \mathrm{~s}$ and $2.09 \mathrm{~s}$ respectively, and the mean value of them is $-513.79 \mathrm{~mm}$, which could ensure the quick shaking off of soil from the oscillating plate. While in 0.26-2.09 $\mathrm{s}$ during which the oscillating plate is closed, its displacement became positive, with interval average value of $18.66 \mathrm{~mm}$. The reason for this situation is quick-return motion during closing process of the oscillating plate, which makes the plate quickly reset and rush upward instantly under the influence of the hinge. This is also the main reason for the soil scattering on the film surface in crosswise soil belt covering.

It can be concluded from the displacement and time variation curve of the oscillating plate that, the displacements of repeated opening and closing of the oscillating plate had some differences in different cycles, but the overall variation trend was basically the same. Therefore the consistency in crosswise soil belt covering and stability of soil amount could be ensured. 


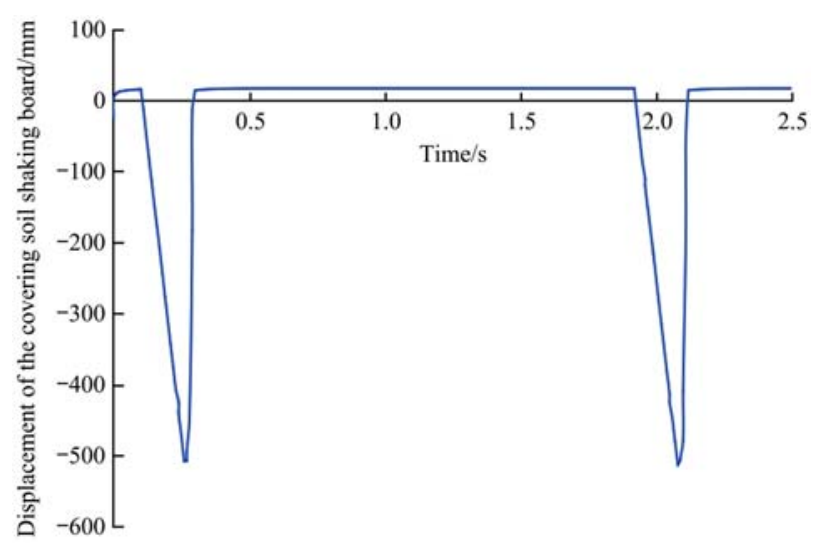

Figure 10 Displacement of the oscillating plate

\subsection{Variation process of covered soil amount}

Due to the special agronomic requirements for double ridges with whole plastic-film, the seedbed soil-covering device should realize different soil amount covering in different stages, and the soil in both soil grooves and the film-mulched soil in the soil outlets should keep flowing, while the crosswise soil belt should be laid intermittently, as is shown in Figure 11. Therefore, it is necessary to further analyze the process of soil covering variation process, and observe the soil movement status in the areas within the yellow frame and red frame.

Figure 12 shows the variation of different soil amount during different soil covering stages of the seedbed soil covering device.

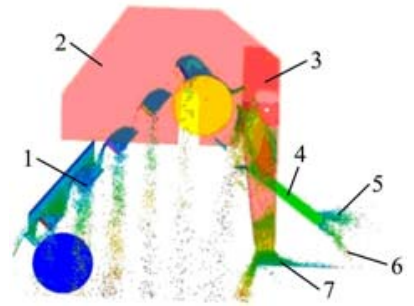

a. Operation model for the seedbed soil covering device

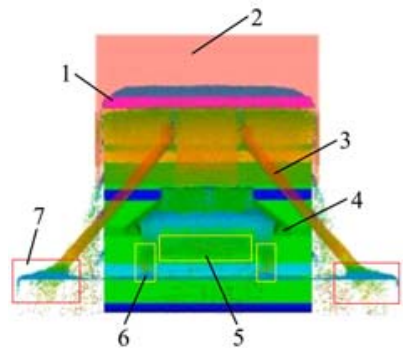

b. Different soil covering areas

1. Scraper type soil elevator 2. Soil covering enclosure 3. Side soil groove 4. Oscillating plate 5. Crosswise soil belt 6 . Soil covering in the ditch of small ridge 7. Soil covering on the big ridge

Figure 11 Different operation areas for the seedbed soil covering device

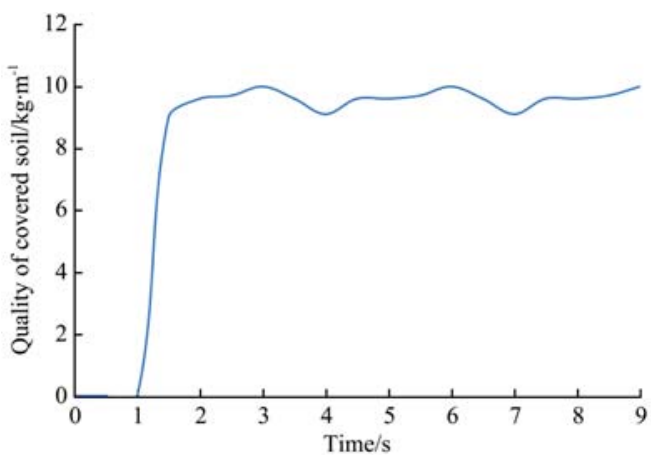

Figure 12 Variation curve of covered soil amount
The variation curve of covered soil amount shows that, during $0 \mathrm{~s}$ and $1.0 \mathrm{~s}$, the soil covering device of the combined operation machine did not deliver the soil to the soil grooves and the oscillating plate, so the soil amount in the seedbed per unit length was $0 \mathrm{~kg} / \mathrm{m}$. From $1.0 \mathrm{~s}$ to $3.0 \mathrm{~s}$, the soil amount kept increasing, especially after $1.5 \mathrm{~s}$, the soil was gradually delivered stably into the soil grooves and the crosswise belt oscillating plate, and the covered soil amount kept over $9 \mathrm{~kg} / \mathrm{m}$. At the instant of opening of oscillating plate in the 3rd second, the amount of covered soil reached maximum, which was $9.98 \mathrm{~kg} / \mathrm{m}$. Then the amount of covered soil showed a cyclical period of $3.0 \mathrm{~s}$ with the repetitive work of the seedbed soil covering device, and the amount of soil covering kept relatively stable.

\section{Verification test}

\subsection{Test conditions and materials}

The field performance test of the crosswise-belt type whole plastic-film ridging-mulching corn seeder was carried out in Tao River Tractor Manufacturing Co., Ltd., Gansu Province, which is Experimental Field of the Gansu Agricultural University Lintao Dry Farming Equipment Experts Courtyard, the field performance test of the crosswise belt type whole plastic-film ridging-mulching corn seeder on double ridges was carried out (Figure 13). The soil in the test site was loessal soil with soil moisture content of $14.9 \%-16.1 \%$, soil bulk density of $1300 \mathrm{~kg} / \mathrm{m}^{3}$, soil compactness was $<0.16 \mathrm{MPa}$. The test field was flat, loose with few weeds. A white roll-shaped mulch film (with thickness of $0.01 \mathrm{~mm}$ ) was installed on the attached film-covering device, and pulled under unfolding roll to the ground ${ }^{[23]}$. The supporting power of the working machine was $22.1 \mathrm{~kW}$ Tao River-304 wheeled tractor, with advancing speed of $0.50 \mathrm{~m} / \mathrm{s}$ in the test.

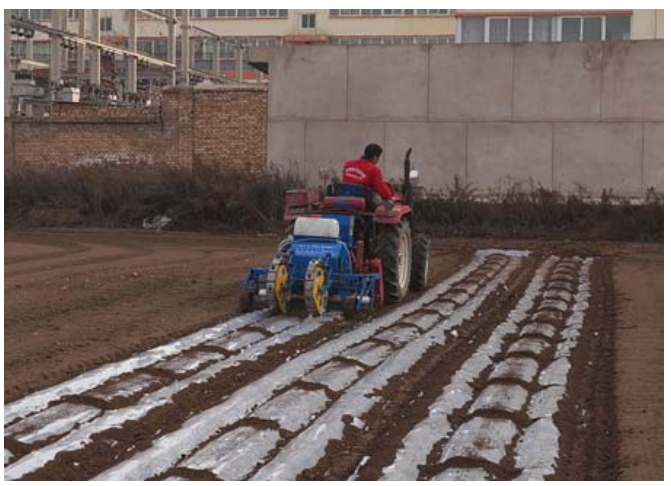

Figure 13 Field performance test of combined machine

\subsection{Test scheme and method}

According to NY/T 986-2006, the standard for working quality of film laying machine; DB62/T 1935-2010, the standard for operational procedures and working quality acceptance of whole plastic-film laying machine on double ridges; the standard for technical specification on for whole plastic-film corn mechanization on double ridges, the qualified rate of soil covering width at film edge and width of crosswise soil belts, qualified rate of soil thickness on the seedbed, qualified rate of sowing depth and qualified rate of spacing between crosswise soil belts.

The measuring points for the qualified rate of soil covering width at film edge and width of crosswise soil belts, qualified rate of soil thickness on the seedbed, qualified rate of sowing depth and qualified rate of spacing between crosswise soil belts were randomly selected. At each measuring point, soil covering width at film edge and width of crosswise soil belts, soil thickness on the seedbed, sowing depth were measured and averaged respectively: 


$$
\begin{aligned}
& Y_{1}=\frac{m_{1}}{m_{0}} \times 100 \% \\
& Y_{2}=\frac{m_{2}}{m_{0}} \times 100 \% \\
& Y_{3}=\frac{m_{3}}{m_{0}} \times 100 \% \\
& Y_{4}=\frac{m_{4}}{m_{0}} \times 100 \%
\end{aligned}
$$

where, $Y_{1}$ is qualified rate of covered soil width on the seedbed, \%; $Y_{2}$ is the qualified rate of soil covering width at film edge, $\% ; Y_{3}$ is the qualified rate of width of crosswise soil belts, $\% ; Y_{4}$ is the qualified rate of sowing depth under film, $\% ; m_{0}$ is total number of measuring points; $m_{1}$ is qualified measuring points in soil covering width at film edge; $m_{2}$ is qualified measuring points in width of crosswise soil belts; $m_{3}$ is qualified measuring points in covered soil thickness on the seedbed; $m_{4}$ is qualified measuring points in sowing depth.

A length of $15 \mathrm{~m}$ seedbed of whole plastic-film mulching on double ridges was randomly selected, and the spacing of the crosswise soil belts was measured, and $(1500 \pm 25) \mathrm{mm}$ was identified as qualified. The average measured values of 10 operation plots were taken as test result. The equation for the qualified rate of the spacing between crosswise soil belts is:

$$
Y_{5}=\frac{t_{1}}{t_{0}} \times 100 \%
$$

where, $Y_{5}$ is the qualified rate of the spacing between crosswise soil belts, $\% ; t_{0}$ is total number of measuring points; $t_{1}$ is number of qualified measuring points in spacing of crosswise soil belts.

\subsection{Test results and analysis}

The field test result of the crosswise-belt type whole plastic-film ridging-mulching corn seeder on double ridges is shown in Table 3.

Table 3 Field test result

\begin{tabular}{lcc}
\hline \multicolumn{1}{c}{ Test indexes } & Standard values & Value \\
\hline Qualified rate of soil covering width at film edge/\% & $\geq 90$ & 96.1 \\
Qualified rate of width of crosswise soil belts/\% & $\geq 90$ & 94.5 \\
Qualified rate of soil covering width at film edge/\% & $\geq 90$ & 95.3 \\
Qualified rate of sowing depth under film/\% & $\geq 75$ & 93.6 \\
Qualified rate of spacing of crosswise soil belts/\% & $\geq 90$ & 89.3 \\
\hline
\end{tabular}

Test result shows that, all the test indexes of the crosswise-belt type whole plastic-film ridging-mulching corn seeder on double ridges could meet the requirements of corresponding national standards. It was observed in the test that, the stable operation performance of seedbed soil covering device and the crosswise belt soil covering mechanism, so the qualified rate of soil covering width at film edge, qualified rate of width of crosswise soil belts, qualified rate of soil covering width at film edge and other indicators were higher than $94 \%$, it ensuring the quality of seed bed construction. By adjusting the simulated sowing depth device, which was ensured that the qualified rate of sowing depth under film was more than $90 \%$. But when the operation ground is rough with many soil clods and stones, wheel slippage of the working machine may be easily caused, resulting in failure of starting the crosswise belt type soil covering device. This is also one of the main factors for low qualified rate between crosswise soil belts of the sample machine.

In the practical operation of the prototype, the differences of soil agglomeration degree and the variation range of soil moisture content in rotary tillage were large, which would lead to a rather complex process of ridging, mulching and seeding. However, it limited by the simulation means, the complicated actual operation process was simplified, and only the simulation and experimental on the seed bed soil covering operation process was carried out, which was different from the actual operation process.

Based on Figures 14a, 14b, the comparison on working performances of simulated seedbed soil covering and practical soil covering showed basic consistence, and verified the soil covering model by the discrete element method. Thus it is feasible to simulate the whole plastic-film crosswise belt and film edge soil covering on double ridges by EDEM.

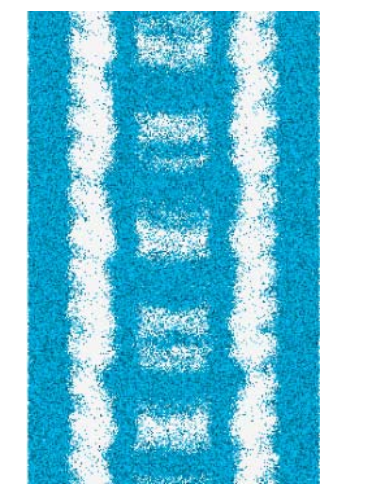

a. Effects of simulated soil covering

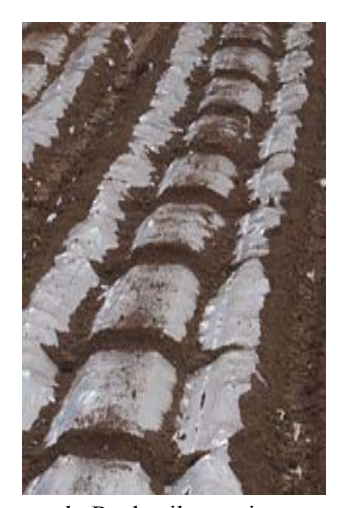

b. Real soil covering
Figure 14 Comparison of soil covering effect

\section{Conclusions}

1) Considering the agronomic requirements of whole plastic-film sowing on double ridges, a kind of crosswise-belt type whole plastic-film combined operation machine for ridging-mulching on double ridges was developed to determine the transmission system, and the seedbed soil covering device and crosswise belt soil covering mechanism, profiling sowing depth adjustment mechanism were also designed. Its key working parameters were analyzed and calculated based on related requirements on its working performance.

2) EDEM was applied in numerical simulation of the crosswise soil covering and soil covering on film edge. The delivery, distribution and motion status of elevated soil in the scraper type soil elevator, soil covering enclosure, soil grooves on both sides and the oscillating plate were obtained, also the variation rules of velocity of oscillating plate, displacement of oscillating plate and amount of covered soil with time were also explored. The entire opening and closing process of the oscillating plate in laying crosswise soil belts required only $0.06 \mathrm{~s}$, and the covered soil amount kept over $9 \mathrm{~kg} / \mathrm{m}$. The amount of covered soil showed a cyclical period of $3.0 \mathrm{~s}$ with the repetitive work of the seedbed soil covering device, and the amount of soil covering kept relatively stable. Then the factors affecting the soil covering effect at different positions in the mechanization process of the whole plastic-film seedbed on double ridges were clarified.

3) Field test results show that, the qualified rate of seedbed soil covering thickness at film ridge was $96.1 \%$, qualified rate of crosswise soil belt width was $94.5 \%$, the qualified rate of covered soil thickness was $93.6 \%$, the qualified rate of sowing depth under film was $89.3 \%$, and the qualified rate of spacing between crosswise soil belts was $93.6 \%$. All the test indexes could meet the related requirements of national standards, and test result could meet the design requirement and the device can realize the mechanization process of the whole plastic-film seedbed on double 
ridges. Comparison on working performances of simulated seedbed soil covering and practical soil covering showed basic consistence, and verified the soil covering model by discrete element method.

\section{Acknowledgements}

The authors acknowledge that this work was financially supported by National Natural Science Foundation of China (Grant No. 51775115; No. 51405086), China Agriculture Research System (CARS-14-1-28).

\section{[References]}

[1] Zhou L M, Jin S L, Liu C A, Xiong Y C, Si J T, Li X G, Gan Y T, Li F M. Ridge-furrow and plastic-mulching tillage enhances maize-soil interactions: opportunities and challenges in a semiarid agroecosystem. Field Crops Research, 2012; 126: 181-188.

[2] Qin S H, Zhang J L, Dai H L, Wang D, Li D M. Effect of ridge-furrow and plastic-mulching planting patterns on yield formation and water movement of potato in a semi-arid area. Agricultural Water Management, 2014; 131: 87-94.

[3] Dai F, Zhao W Y, Wang J X, Zhang F W, Feng F X, Zhang F Y. Physical properties of mechanical covering film seedbed with corn whole plastic-film mulching on double ridges. International Agricultural Engineering Journal, 2017; 26(4): 149-156.

[4] Dai F, Zhao W Y, Song X F, Zhang F W, Feng F X. Working process analyses of direct insert hill-device with corn whole plastic-film mulching on double ridges based on EDEM. International Agricultural Engineering Journal, 2017; 26(4): 124-131.

[5] Dai F, Zhao W Y, Ma M Y, Wang J X, Shi L R, Ma J M. Optimization of operation machine for tillage-fertilization and spraying-filming on double ridges. Transactions of the CSAM, 2016; 47(1): 83-90. (in Chinese)

[6] Li L, Zhang Q, Feng Y C, Nie D, Sun J, Yan M, Wang B, Huang G J. All-film double-furrow sowing improving water and salt conditions and increasing maize yield in saline soil of cold and arid area. Transactions of the CSAE, 2016; 32(5): 96-103. (in Chinese)

[7] Zhao F. Research and application development for the techniques of whole plastic-film mulching on double ridges and planting in catchment furrows in dry land. Agricultural Research in the Arid Areas, 2016; 34(4): 211-217. (in Chinese)

[8] Wang X F, Hu C, Lu B, Jiang J Y, Hou S L. Wind tunnel test on damages of plastic film under the wind-sand effect in south Xinjiang of China. International Agricultural Engineering Journal, 2017; 26(1): 16-23.

[9] Borut $G$, Dea B. Incorporation of a ridge-furrow-ridge rainwater harvesting system with mulches in high-value plant production. Irrigation and Drainage, $2011 ; 60(4)$ : 518-525.
[10] Zhang J J, Fan T L, Dang Yi, Zhao G, Wang L, Li S Z. The effects of density and nitrogen management on the yield and physiological indices of spring maize under plastic-covered ridge and furrow planting in loess plateau east of Gansu. Scientia Agricultura Sinica, 2015; 48(22): 4574-4584. (in Chinese)

[11] Sun W, Liu X L, Shi L R, Zhang H, Liu Q W, Wu J M. Covering soil on plastic-film characteristics of scraper lifting belt mechanism. Journal of Mechanical Engineering, 2016; 52(7): 38-45. (in Chinese)

[12] Sun W, Liu X L, Zhang H, Wang H C, Tian B. Design of potato casingsoil planter in all-in-one machine combined with fertilizing, sowing, ridging, complete film mulching and planting line covering. Transactions of the CSAE, 2017; 33(20): 14-22. (in Chinese)

[13] Miroslav B, Robert B. Experimental tests of selected constituents of movement resistance of the belt conveyors used in the underground mining. Procedia Earth and Planetary Science, 2015; 15: 711-720.

[14] Manuel J C, Luis A. Dynamic transition in conveyor belt driven granular flow. Powder Technology, 2015; 272: 290-294.

[15] Dai F, Zhao W Y, Zhang F W, Wu Z W, Song X F, Wu Y F. Optimization and experiment of operating performance of collector for corn whole plastic film mulching on double ridges. Transactions of the CSAE, 2016; 32(18): 50-60. (in Chinese)

[16] Zhao H, Wang R Y, Ma B L, Xiong Y C, Qiang S C, Wang C L, Liu C A Li F M. Ridge-furrow with full plastic film mulching improves water use efficiency and tuber yields of potato in a semiarid rainfed ecosystem. Field Crops Research, 2014; 161: 137-148.

[17] Wang J W, Zhou W Q, Tian L Q, Li S W, Zhang Z. Virtual simulation analysis and verification of seed-filling mechanism for dipper hill-drop precision direct rice seeder. Int J Agric \& Biol Eng, 2017; 10(6): 77-85.

[18] Ucgul M, Fielke J M, Saunders C. 3D DEM tillage simulation: validation of a hysteretic spring (plastic) contact model for a sweep tool operating in a cohesionless soil. Soil and Tillage Research, 2014; 144(4): 220-227.

[19] Ucgul M, Fielke J M, Saunders C. Three-dimensional discrete element modelling of tillage: determination of a suitable contact model and parameters for a cohesionless soil. Biosystems Engineering, 2014; 121(2): $105-117$.

[20] Dai F, Song X F, Zhao W Y, Han Z S, Zhang F W, Zhang S L. Motion simulation and test on threshed grains in tapered threshing and transmission device for plot wheat breeding based on CFD-DEM. Int $\mathrm{J}$ Agric \& Biol Eng, 2019; 12(1): 66-73.

[21] Zhao Z, Li Y M, Liang Z W, Gong Z Q. DEM simulation and physical testing of rice seed impact against a grain loss sensor. Biosystems Engineering, 2013; 116: 410-419.

[22] Oldal I, Safranyik F. Extension of silo discharge model based on discrete element method. Journal of Mechanical Science \& Technology, 2015; 29(9): 3789-3796.

[23] Jin X, Li Q W, Zhao K X, Zhao B, He Z T, Qiu Z M. Development and test of an electric precision seeder for small-size vegetable seeds. Int $\mathrm{J}$ Agric \& Biol Eng, 2019; 12(2): 75-81. 